\title{
EXISTENCE RESULTS FOR A CAPUTO-HADAMARD TYPE FRACTIONAL BOUNDARY VALUE PROBLEM
}

\author{
ABdelouaheb Ardjouni
}

Abstract. The main purpose of this paper is to establish the existence and uniqueness of mild solutions for a Caputo-Hadamard type fractional boundary value problem. Existence and uniqueness results are based on the Krasnoselskii fixed point theorem and the Banach contraction mapping principle. Finally, two examples are given to illustrate this work.

Mathematics subject classification (2020): 34A08, 34A12.

Keywords and phrases: Fractional boundary value problems, existence, uniqueness, fixed point theorems.

\section{REFERENCES}

[1] B. Ahmad And S. K. NTOUYAs, Existence and uniqueness of solutions for Caputo-Hadamard sequential fractional order neutral functional differential equations, Electron. J. Differential Equations 2017, 36 (2017), 1-11.

[2] A. Ardjouni, Positive solutions for nonlinear Hadamard fractional differential equations with integral boundary conditions, AIMS Mathematics 4, 4 (2019), 1101-1113.

[3] A. ARdjouni And A. Djoudi, Positive solutions for first-order nonlinear Caputo-Hadamard fractional relaxation differential equations, Kragujevac Journal of Mathematics 45, 6 (2021), 897-908.

[4] A. ARdjouni AND A. DJoudi, Initial-value problems for nonlinear hybrid implicit Caputo fractional differential equations, Malaya Journal of Matematik 7, 2 (2019), 314-317.

[5] A. ARdjouni AND A. Djoudi, Approximating solutions of nonlinear hybrid Caputo fractional integro-differential equations via Dhage iteration principle, Ural Mathematical Journal 5, 1 (2019), $3-12$.

[6] A. ARdjouni AND A. DJoudi, Existence and uniqueness of positive solutions for first-order nonlinear Liouville-Caputo fractional differential equations, São Paulo J. Math. Sci. 14, (2020), 381-390.

[7] A. ARdjouni, A. LACHOURI AND A. DJOUdi, Existence and uniqueness results for nonlinear hybrid implicit Caputo-Hadamard fractional differential equations, Open Journal of Mathematical Analysis 3, 2 (2019), 106-111.

[8] Z. BAI AND H. LÜ, Positive solutions for boundary value problem of nonlinear fractional differential equation, J. Math. Anal. Appl. 311, (2005) 495-505.

[9] Z. B. BAI AND T. T. QIU, Existence of positive solution for singular fractional differential equation, Appl. Math. Comput. 215, (2009), 2761-2767.

[10] H. Boulares, A. ARdJOUni AND Y. LASKRI, Positive solutions for nonlinear fractional differential equations, Positivity 21, (2017), 1201-1212.

[11] D. Delbosco AND L. Rodino, Existence and uniqueness for a nonlinear fractional differential equation, J. Math. Anal. Appl. 204, (1996), 609-625.

[12] E. Kaufmann And E. MBoumi, Positive solutions of a boundary value problem for a nonlinear fractional differential equation, Electron. J. Qual. Theory Differ. Equ. 2008, 3 (2008), 1-11.

[13] A. A. Kilbas, H. M. Srivastava And J. J. Trujillo, Theory and Applications of Fractional Differential Equations, Elsevier, Amsterdam, 2006.

[14] C. Kou, H. ZHOU AND Y. YAN, Existence of solutions of initial value problems for nonlinear fractional differential equations on the half-axis, Nonlinear Anal. 74, (2011), 5975-5986. 
[15] K. Q. LAN AND W. Lin, Positive solutions of systems of Caputo fractional differential equations, Communications in Applied Analysis 17, 1 (2013), 61-86.

[16] M. MATAR, On existence of positive solution for initial value problem of nonlinear fractional differential equations of order $1<\alpha \leqslant 2$, Acta Math. Univ. Comenianae LXXXIV, 1 (2015), 51-57.

[17] K. S. Miller And B. Ross, An Introduction to the Fractional Calculus and Fractional Differential Equations, Wiley, New York, 1993.

[18] S. NiYom, S. K. NTOUYAS, S. LaOpRasittichoK AND J. TARiboon, Boundary value problems with four orders of Riemann-Liouville fractional derivatives, Adv. Difference Equ. 2016, 165 (2016), $1-14$.

[19] S. K. NTOUYAS AND J. TARIBOON, Fractional boundary value problems with multiple orders of fractional derivatives and integrals, Electron. J. Differential Equations 2017, 100 (2017), 1-18.

[20] I. Podlubny, Fractional Differential Equations, Academic Press, San Diego, 1999.

[21] D. R. Smart, Fixed Point Theorems, Cambridge Uni. Press., Cambridge, 1980.

[22] C. Wang, R. Wang, S. Wang And C. Yang, Positive Solution of Singular Boundary Value Problem for a Nonlinear Fractional Differential Equation, Bound. Value Probl. 2011, (2011), Art ID 297026.

[23] C. WANG, H. Zhang AND S. WANG, Positive solution of a nonlinear fractional differential equation involving Caputo derivative, Discrete Dynamics in Natural and Society 2012, (2012), Art ID425408.

[24] S. ZHANG, Existence results of positive solutions to boundary value problem for fractional differential equation, Positivity 13, 3 (2009), 583-599.

[25] S. Zhang, The existence of a positive solution for a fractional differential equation, J. Math. Anal. Appl. 252, (2000), 804-812. 